\title{
Application of the Marginal Beta-Binomial Model in Estimation the Overall Odds of Obesity Among Iranian Adults: Meta-Analysis Method
}

\author{
Atefeh Zeinolabedini ${ }^{1}$, Akbar Biglarian ${ }^{2}$, Behjat Seifi ${ }^{3}$ and Enayatollah Bakhshi ${ }^{1,{ }^{*}}$ \\ ${ }^{1}$ Department of Biostatistics, University of Social Welfare and Rehabilitation Sciences, Tehran, Iran \\ ${ }^{2}$ Department of Biostatistics, Social Determinants of Health Research Center, University of Social Welfare and Rehabilitation Sciences (USWRS), Tehran, Iran \\ ${ }^{3}$ Department of Physiology, Faculty of Medicine, Tehran University of Medical Sciences, Tehran, Iran \\ "Corresponding author: Department of Biostatistics, University of Social Welfare and Rehabilitation Sciences, Koudakyar St., Evin, Tehran, Iran. Tel: +98-2122180146, Email: \\ bakhshi@razi.tums.ac.ir
}

Received 2018 March 07; Revised 2018 October 17; Accepted 2018 December 01.

\begin{abstract}
Context: To obtain accurate and reliable estimation of overall obesity odds ratio (OR) a statistical method is needed to be designed to account for heterogeneity among studies. The marginal beta-binomial model is a new method with attractive features that make it robust for meta-analysis.

Objectives: The aim of this study is the estimation of overall obesity OR among Iranian adults with particularly attention to age, sex, place of residence, and smoking status.

Data Sources: We systematically reviewed all studies regarding obesity in Iranian adults in national and international journals that are published between 1990 and 2017, including PubMed, Scopus, SID, Google Scholar, Magiran, and IranMedex. The R software was used for data analysis and obtaining overall obesity OR using the marginal beta-binomial model.

Results: A total of 18 studies, with a sample size of 258283, were included in our analysis. Results showed that increasing age, female sex, and residence in urban areas increases the odds of obesity. Using the age group 20 - 30 years as the reference, the overall obesity ORs for $30-40,40-50,50-60$, and 60+ years were 2.13, 3.33, 3.15, and 2.33, respectively. The overall obesity OR for women was 2.35 , compared with men. The estimated odds of obesity were $53 \%$ higher for urban adults. Smoking has a negative effect on obesity; the OR of obesity for smokers was 0.48 compared with non-smokers.

Conclusion: Consistent results in our research can be used as a basis to reinforce health programs for prevention and treatment of obesity in Iran.
\end{abstract}

Keywords: Obesity, OR, Marginal Beta-Binomial

\section{Context}

Obesity is known as an epidemic in the 21st century (13). It is an important risk factor for chronic disease such as cardiovascular disease, hypertension, cancer, diabetes mellitus, and gallbladder disease (4-8). In 2016, more than 1.9 billion adults, 18 years and older, were overweight. Of these, over 650 million were obese (9). Considering the increasing rate of obesity prevalence in Iran (10-13) we need accurate data to design programs for preventive and treatment of obesity and determine relevant health policies to prevent health risks (14). Obesity is substantially unequal in various regions in Iran that are influenced by socio-economic status and demographic factors such as age, gender, difference in living classes, education, occupation, and marital status (15). There are several studies in many provinces of Iran that assess the association of obesity and related risk factors and report the prevalence of obesity among adults. However, there is the heterogeneity among these studies due to different culture, lifestyle, and socio-economic status (16-18). To account for this heterogeneity among studies and to achieve the greater precision we need to conduct a meta-analysis. Meta-analysis is a statistical procedure of synthesizing the available evidences from multiple studies. The marginal beta-binomial is a new statistical method for meta-analysis that is more robust in comparison with existing models such as bivariate generalized linear mixed model and the Sarmanov betabinomial model (19). This model, based on the composite likelihood approach, has several attractive features (18).

\section{Objectives}

The aim of this study is the estimation of overall obesity odds ratio (OR) in Iranian adults with particular atten- 
tion to age, gender, place of residence, and smoking status using the marginal beta-binomial model.

\section{Data Sources}

\subsection{Search Strategy}

To identify the published literatures between 1990 2017 that assessed the obesity and related risk factors in Iranian adults, we systematically reviewed several national electronic databases including: SID (Scientific Information Database), Iran-Medex, and IranDoc. In addition, we also used international databases, such as PubMed, ISI (Institute of Scientific Information), and Scopus for extraction data. We used the medical subject heading (Mesh) "obesity" and "body mass index" combined with Iran and equivalent Persian keyword for Iranian database. We also used manually search to find literatures that were not found in the electronic search and checked the reference of the selected literature for maximization of the sensitivity of our search. There was no restriction on language.

\subsection{Definition}

The most prevalent and practical indicator for evaluation of overweight and obesity is the body mass index (BMI) (20). Obesity is a response variable in relevant studies that, according to the definition of the World Health Organization, is defined as BMI > 30 for adult populations (at least 18 years of age) (9). We included related studies based on anthropometric measure (height and weight) for determining obesity.

\subsection{Study Selection}

\subsubsection{Inclusion and Exclusion Criteria}

At first, all founded studies were review based on their title by two study investigators independently and nonrelevant studies, duplications and studies that focused on female sex were deleted. Then, the remaining articles were reviewed by abstract in more detail and those who have small study populations (sample less than 100 people), nonrandom sample, did not have any information for applying our method, and those who did not report adjusted ORs were excluded from study. Our study also included studies that have attention to age, sex, place of residence, and smoking status or at least one of them. Every process was reviewed by one expert reviewer to decide on the case.

\subsubsection{Data Extraction and Quality Assessment}

We generated a simple checklist to assess the quality of included studies. The quality assessment form has three parts: General information regarding the study, sampling quality, and measurement quality.
Each study had a unique code and its general information, such as the name and name of the corresponding author, have been inserted at the top of the form. The sampling quality refers to sample size and sampling design and the measurement quality includes type of measurement tools and accuracy of measurement. The final decision was based on the total scores obtained by each paper in the ranking scale of: Excellent (13 - 19), good (6 - 12), or poor $(\leq 5)$. Poor quality papers have been deleted and two other categories were considered for data extraction processes. All eligible papers have been reviewed and the required information have been extracted. We summarized data and extracted information such as name of first author, year of study, sample population, and reported obesity OR from eligible studies in Table 1 . There was a variation in age group category and we selected five 10-year aged group ((20 - 30), (30 - 40), (40 - 50), (50 - 60), and (60+)) due to its abundance in the studies.

\subsection{Statistical Analysis}

Due to the heterogeneity between studies in a metaanalysis, statistical methods need to be designed to account for this problem. Among the existing model, marginal beta-binomial method proposed by Chen et al. (19) is based on the composite likelihood method.

\subsubsection{Overview of the Marginal Beta-Binomial Approach}

According to the method proposed by Chen et al. (19) for the $\mathrm{i}^{\text {th }}$ study in a meta-analysis, let denote $\mathrm{n}_{\mathrm{i11}}, \mathrm{n}_{\mathrm{i} 22}, \mathrm{n}_{\mathrm{i} 21}$, $\mathrm{n}_{\mathrm{i} 12}, \mathrm{n}_{\mathrm{i1}}$, and $\mathrm{n}_{\mathrm{i} 2}$ be the numbers of true positives, true negatives, false positives, false negatives, obese subjects, and non-obese subjects, respectively, and $\mathrm{Se}_{\mathrm{i}}$ and $\mathrm{Sp}_{\mathrm{i}}$ be the sensitivity and specificity, respectively.

The bivariate generalized linear mixed effects model, which is commonly used in meta-analysis (33), assumes that the numbers of true positives and true negatives are conditional independent and follow binomial distribution, which is,

$$
\left(\mathrm{n}_{\mathrm{i11}}, \mathrm{n}_{\mathrm{i} 22}\right) \mid\left(\mathrm{n}_{\mathrm{i} 1}, \mathrm{n}_{\mathrm{i} 2}, \mathrm{Se}_{\mathrm{i}}, \mathrm{Sp}_{\mathrm{i}}\right) \sim \operatorname{Bin}\left(\mathrm{n}_{\mathrm{in1}} \mid \mathrm{n}_{\mathrm{i} 1}, \mathrm{Se}_{\mathrm{i}}\right) \times\left(\mathrm{n}_{\mathrm{i} 22} \mid\right.
$$
$\left.\mathrm{n}_{\mathrm{i} 2}, \mathrm{Sp}_{\mathrm{i}}\right)$

The additional assumption for using the Sarmanov beta-binomial model is that the joint distribution of the Sei and Spi are assumed to follow the Sarmanov distribution family (34).

Then, the marginal distribution of $\left(\mathrm{n}_{\mathrm{i1}}, \mathrm{n}_{\mathrm{i} 22}\right)$ is specified and it is composition of the beta-binomial distributions are given by

$$
\begin{aligned}
& P_{\text {beta-bin }}\left(n_{i 11} ; n_{i 1}, a_{1}, b_{1}\right) \\
& =\left(\begin{array}{c}
n_{i 1} \\
n_{i 11}
\end{array}\right) \frac{\operatorname{beta}\left(n_{i 11}+a_{1}, n_{i 1}-n_{i 11}+b_{1}\right)}{\left(\operatorname{beta}\left(a_{1}, b_{1}\right)\right)} \\
& P_{\text {beta-bin }}\left(n_{i 22} ; n_{i 2}, a_{2}, b_{2}\right) \\
& =\left(\begin{array}{c}
n_{i 2} \\
n_{i 12}
\end{array}\right) \frac{\operatorname{beta}\left(n_{i 22}+a_{2}, n_{i 2}-n_{i 22}+b_{2}\right)}{\left(\operatorname{beta}\left(a_{2}, b_{2}\right)\right)}
\end{aligned}
$$




\begin{tabular}{|c|c|c|c|c|c|c|c|c|c|c|c|c|c|c|}
\hline \multirow{3}{*}{ Study } & \multirow{3}{*}{ First Author } & \multirow{3}{*}{ Year of Study } & \multirow{3}{*}{ Sample Size } & \multicolumn{11}{|c|}{ Related Factor } \\
\hline & & & & \multicolumn{5}{|c|}{ Age } & \multicolumn{2}{|c|}{ Sex } & \multicolumn{2}{|c|}{ Place of Residence } & \multicolumn{2}{|c|}{ Smoking Status } \\
\hline & & & & $20-30$ & $30-40$ & $40-50$ & $50-60$ & +60 & Male & Female & Rural & Urban & Non-Smoker & Smoker \\
\hline 1 & Bakhshi (21) & 2000 & 27869 & 1 & 2.44 & 3.52 & 3.40 & 3.02 & 1 & 2.40 & 1 & 1.98 & 1 & 0.65 \\
\hline 2 & Bakhshi (21) & 2007 & 26716 & 1 & 2.61 & 3.66 & 3.52 & 3.25 & 1 & 2.35 & 1 & 1.63 & 1 & 0.69 \\
\hline 3 & Bakhshi (21) & 2009 & 20917 & 1 & 2.42 & 3.74 & 3.52 & 3.13 & 1 & 2.57 & 1 & 1.49 & 1 & 0.77 \\
\hline 4 & Bakhshi (21) & 2011 & 8425 & 1 & 2.16 & 3.41 & 3.25 & 2.82 & 1 & 1.58 & 1 & 1.46 & 1 & 0.57 \\
\hline 5 & Bakhshi (22) & 2016 & 26551 & 1 & 2.27 & 3.18 & 3.12 & 2.20 & 1 & 2.90 & 1 & 1.92 & 1 & 0.39 \\
\hline 6 & Dalvand (23) & 2015 & 18990 & 1 & 1.95 & 2.73 & 2.73 & 2.30 & 1 & 2.85 & 1 & 1.57 & 1 & 0.37 \\
\hline 7 & Ahmadi (24) & 2010 & 1000 & & & & & & 1 & 3.00 & & & & \\
\hline 8 & Veghari (25) & 2006 & 2471 & & & & & & & & 1 & 1.5 & & \\
\hline 9 & Khabazkhoob (26) & 2003 & 4565 & 1 & 2.29 & 3.93 & 4.36 & 3.55 & 1 & 2.27 & & & & \\
\hline 10 & Abdollahi (27) & 2005 & 5000 & & & & & & 1 & 1.74 & & & & \\
\hline 11 & Moghimi-Dehkordi (28) & $2007 \cdot 2008$ & 3000 & 1 & 2.37 & 2.71 & 2.41 & 1.71 & 1 & 2.01 & & & & \\
\hline 12 & Hosseinpanah (29) & $1991-2001$ & 4402 & 1 & 1.97 & 3.51 & 4.27 & 2.65 & 1 & 2.40 & & & & \\
\hline 13 & Hosseinpanah (29) & $2002 \cdot 2005$ & 4402 & 1 & 2.06 & 4.73 & 4.29 & 2.82 & 1 & 2.60 & & & & \\
\hline 14 & Hosseinpanah (29) & $2006-2008$ & 4402 & 1 & 1.71 & 2.58 & 2.62 & 1.46 & 1 & 2.30 & & & & \\
\hline 15 & Janghorbani (30) & $2004-2005$ & 89404 & & & & & & 1 & 2.62 & 1 & 1.47 & 1 & 0.65 \\
\hline 16 & Azadbakht (31) & $1999-2001$ & 9984 & 1 & 2.21 & 3.64 & 4.38 & 3.2 & 1 & 2.49 & & & & \\
\hline 17 & Rashidy-pour (11) & $2005-2006$ & 3799 & & & & & & 1 & 3.30 & 1 & 1.34 & & \\
\hline 18 & Khabazkhoob (32) & $2009-2010$ & 5190 & & & & & & 1 & 3.23 & & & & \\
\hline
\end{tabular}

Thus, the marginalized likelihood, as a function of $\left(a_{1}\right.$, $\mathrm{b}_{1}, \mathrm{a}_{2}, \mathrm{~b}_{2}, \rho$ ), is specified.

By using the working independence assumption (19), the pseudo likelihood is obtained,

$$
\begin{aligned}
& \text { Loglikpseud }\left(a_{1}, a_{2}, b_{1}, b_{2}\right) \\
& \begin{array}{l}
=P_{\text {beta-bin }}\left(n_{i 11} ; n_{i 1}, a_{1}, b_{1}\right) \\
\quad+\sum_{i=1}^{n} P_{\text {beta-bin }}\left(n_{i 22} ; n_{i 2}, a_{2}, b_{2}\right)
\end{array}
\end{aligned}
$$

This pseudo likelihood can be specified by the marginal distribution of the $\mathrm{Se}_{\mathrm{i}}$ and $\mathrm{Sp}_{\mathrm{i}}$, and model is considered as a marginal beta-binomial model.

\section{Results}

In the primary search, we found 105 full text articles based on the related keywords to our topic. After excluding duplications and considering the inclusion and exclusion criteria, finally, 18 studies were selected to enter our study. The number of primary research results and the detailed process to select appropriate studies are shown in Figure 1. These results attributed to 258283 individuals that were included in our study. Table 2 shows the frequency of studies and overall obesity OR with marginal beta-binomial model for each factor separately. Our results revealed an association between the overall obesity OR and sex, age, smoking, and place of residence among Iranian adults.
Record Identified Through Data-based Searching $(\mathrm{n}=105)$

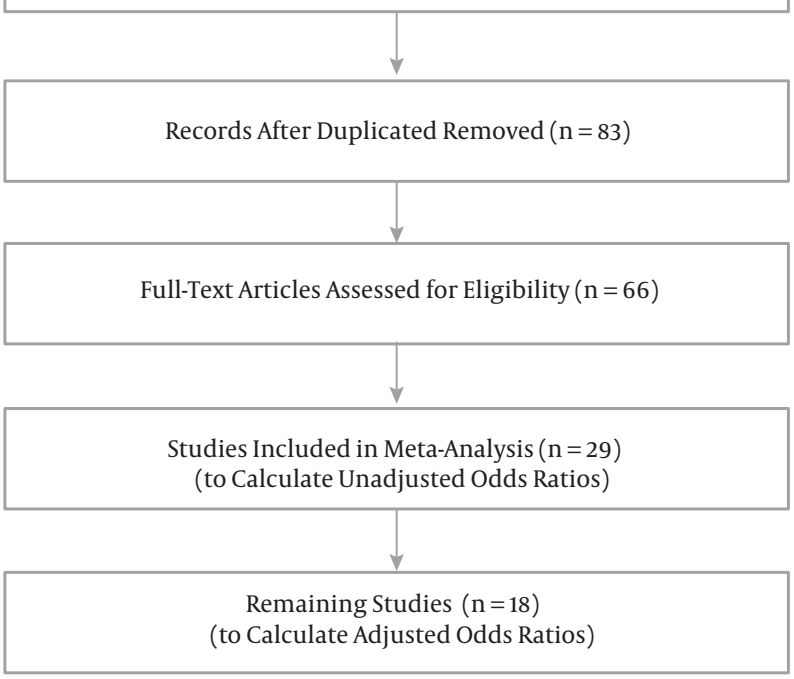

Figure 1. Flow chart of studies assessed and selected for meta-analysis

\subsection{Age}

Based on our age group category, 12 studies included age factor. By increasing age to up to 40 - 50 years old, the odds of obesity increased and it decline thereafter. This range of peak is almost equal in the included studies. With 


\begin{tabular}{|c|c|c|c|c|c|c|}
\hline \multirow[t]{2}{*}{ Variable } & \multicolumn{3}{|c|}{ Unadjusted } & \multicolumn{3}{|c|}{ Adjusted } \\
\hline & Number of Studies & OR & 95\% Confidence Interval & Number of Studies & OR & 95\% Confidence Interval \\
\hline Age, $y$ & 14 & & & 12 & & \\
\hline \multicolumn{7}{|l|}{$20-30$} \\
\hline $30-40$ & & 2.81 & $2.61-3.04$ & & 2.13 & $2.02-2.24$ \\
\hline $40-50$ & & 3.34 & $2.97-3.76$ & & 3.33 & $2.9-3.81$ \\
\hline $50-60$ & & 3.25 & $2.87-3.68$ & & 3.15 & $2.76-3.66$ \\
\hline $60+$ & & 2.43 & $2.11-2.80$ & & 2.33 & $2.03-2.71$ \\
\hline Female sex & 28 & 2.55 & $2.15-2.81$ & 17 & 2.35 & $2.01-2.74$ \\
\hline Residence in an urban area & 13 & 1.61 & $1.47-1.76$ & 9 & 1.53 & $1.42-1.67$ \\
\hline Smoker & 7 & 0.48 & $0.41-0.56$ & 7 & 0.48 & $0.41-0.56$ \\
\hline
\end{tabular}

Abbreviation: OR, odds ratio.

using the marginal beta-binomial model and using the age group of 20 - 30 years as the reference, obesity ORs for 30 $40,40-50,50-60$, and +60 were 2.13 (95\% CI: 2.02 to 2.24 ), 3.33(95\% CI: 2.91 to 3.81), 3.15 (95\% CI: 2.76 to3.66), and 2.33 (95\% CI: 2.03 to 2.71 ), respectively.

\subsection{Sex}

A total of 17 studies had reported the prevalence of obesity both in men and women. There was a strong association between sex and obesity and also a variation in reported obesity OR due to sever heterogeneity among studies. The minimum and maximum of obesity OR for women was 1.58 and 3.30, respectively. The overall obesity OR for women with marginal beta-binomial model is estimated as 2.35 (95\% CI: $2.01-2.74$ ), that is, women have 2.35 times higher odds of obesity in comparison with men.

\subsection{Place of Residence}

A total of nine studies had reported the prevalence of obesity for urban and rural individuals separately. The range of obesity OR was varied between 0.95 and 2.16 . Totally, $19.86 \%$ of urban and $13.96 \%$ of rural people were obese. The overall obesity OR for urban peoples was 1.53 (95\% CI:1.42 to 1.67), compared with rural.

\subsection{Smoking}

There were seven studies on the association between smoking and obesity in eligible studies. The range of obesity OR for smoker subjects varied between 0.37 and 0.77 compared with nonsmokers. The overall obesity OR for smokers with marginal beta-binomial is 0.48 (95\% CI: 0.41 to 0.56 ).

\section{Conclusions}

The increasing rate of overweight and obesity is a serious public health problem in the world. A study of global burden in 2005 projected that the number of overweight and obese people in 2030 will reach to 1.35 billion (7). For this reason, the researcher and policy-makers must plan to prevent obesity and determine a health policy for reliable data. To find a study on obesity in Iranian adults we systematically reviewed all related studies from 1990 to 2017 in Iran. However, there was a large variation obesity rate that is due to the populations more than 75 million living in 31 provinces by different socio-economic factors, such as cultural and lifestyles $(35,36)$ with a different distribution of age and sex. In a recent systematic review in Iranian adults the range of obesity prevalence in national studies was $12.6 \%-25.9 \%$ (37). In our study, we estimate the overall obesity OR by age, sex, place of residence, and smoking status for Iranian adults using the marginal beta-binomial model. Our findings show that here is a positive association between obesity and age, which is similar to other studies in Iran (38-40) and other countries (41). Changes in food intake, energy expenditure, appetite, and body composition that occurs with ageing attributed to this relationship, as well as, decrease in physical activities, poorer lifestyle, and nutritional behaviors are important reasons for increasing obesity with aging (42). However, in earlier ages, up to 50 years, the obesity reached its maximum rate and then began declining steadily thereafter. This decline of obesity in older age is in association with change in lifestyle, change in diet (43), and decrease in survival rate due to less physical activities and developing diabetes and cardiovascular disease. In all included studies, the joint frequency of obesity in women was considerably higher than men in all aged groups. In our study, 25.71\% of woman and $11.66 \%$ of men were obese and the odds of obe- 
sity in women is 2.3 times higher in men. Our results agree with other studies in Iran $(44,45)$ as well as neighboring countries including Saudi Arabia $(46,47)$, Turkey $(48,49)$, Bahrain (50), and Lebanon (51), however, magnitude of the difference between the sexes varies significantly by countries (52). There were dissimilar results in developed countries such as U.S and many European countries that report higher obesity for men (53). In addition, in some developed country such as France, the prevalence of obesity is similar in both genders. This discrepancy between sexes can likely be related to less physical activity, less smoking, secretion of sex hormones, sedentary lifestyle, unhealthy diet, pregnancy, and menopause in women $(54,55)$. There are a few studies in Iran that evaluate the relation between obesity and urban and rural residence. In our study, $19.86 \%$ of urban and $13.96 \%$ of rural individuals were obese, which is similar to other studies where people in urban areas have a higher risk of obesity than rural area individuals. The main reason for this difference can be attributed to less physical activity (sedentary works), unhealthy lifestyle, and tend to eat full-fat food in urban people. It seems that urbanization phenomenon can be an important risk factor for increasing obesity in Iranian adults. Due to the lack of job opportunities, rural residents tend to transition to provincial capital, which is a reason for growing the urban population and obesity. Our finding is similar to some studies in other countries (56). There are some studies with inconsistent results, such as a study in Iran (24) and Turkey, which reported the higher prevalence of obesity in rural areas in comparison to urban areas (57).

Our results show a negative association between smoking and obesity in Iranian adults. All included studies report that obesity is less frequent in smokers than nonsmokers. Smoking can have an influence on body weight by increasing metabolism and reducing the consumption of sweet foods. Nicotine also increases energy expenditure, reduces appetite, and decreases the intake of food (58-60). Therefore, smoking can be related to lower body weight and reducing obesity (61). Studies from Australia (62) and Finland (63) did not find a significant deference in obesity between smokers and non-smokers. Our results are also consistent with some studies that used different methods to determine the obesity OR (39).

One of the limitations of our study is that the other risk factors including education, occupation, and marital status were not used in our investigation. Systematic review depends on the quality of the primary studies that are included, thus, being the main limitation of our study. We have excluded the papers that reported unadjusted ORs, which is a problem in our meta-analysis. Therefore, the number of papers were reduced, which is also another limitation of this study. The use of a new statistical method for estimating odds ratio is a major strength for our study.

\section{Footnotes}

Conflict of Intersts: The authors declare they have no competing interests.

Funding/Support: There was no funding for this report.

\section{References}

1. James PT, Leach R, Kalamara E, Shayeghi M. The worldwide obesity epidemic. Obes Res. 2001;9 Suppl 4:228S-33S. doi: 10.1038/oby.2001.123. [PubMed: 11707546].

2. Popkin BM, Doak CM. The obesity epidemic is a worldwide phenomenon. Nutr Rev. 1998;56(4 Pt 1):106-14. doi: 10.1111/j.17534887.1998.tb01722.x. [PubMed: 9584495].

3. Rossner S. Obesity: The disease of the twenty-first century. Int J Obes Relat Metab Disord. 2002;26 Suppl 4:S2-4. doi: 10.1038/sj.ijo.0802209. [PubMed: 12457290].

4. Egger G, Dixon J. Beyond obesity and lifestyle: A review of 21st century chronic disease determinants. Biomed Res Int. 2014;2014:731685. doi: 10.1155/2014/731685. [PubMed: 24804239]. [PubMed Central: PMC3997940].

5. Flegal KM, Graubard BI, Williamson DF, Gail MH. Excess deaths associated with underweight, overweight, and obesity. JAMA. 2005;293(15):1861-7. doi: 10.1001/jama.293.15.1861. [PubMed: 15840860].

6. Kannel WB, D’Agostino RB, Cobb JL. Effect of weight on cardiovascular disease. Am J Clin Nutr. 1996;63(3 Suppl):419S-22S. doi: 10.1093/ajcn/87.6.1602. [PubMed: 8615332].

7. Kelly T, Yang W, Chen CS, Reynolds K, He J. Global burden of obesity in 2005 and projections to 2030. Int J Obes (Lond). 2008;32(9):1431-7. doi: 10.1038/ijo.2008.102. [PubMed: 18607383].

8. Todd Miller M, Lavie CJ, White CJ. Impact of obesity on the pathogenesis and prognosis of coronary heart disease. J Cardiometab Syndr. 2008;3(3):162-7. doi: 10.1111/j.1559-4572.2008.00004.x. [PubMed: 18983333].

9. World Health Organization. Obesity and overweight. Fact sheet No. 311. World Health Organization; 2006. Available from: http://www.who. $\mathrm{int} /$ mediacentre/factsheets/fs311/en/.

10. Rashidi A, Mohammadpour-Ahranjani B, Vafa MR, Karandish M. Prevalence of obesity in Iran. Obes Rev. 2005;6(3):191-2. doi: 10.1111/j.1467789X.2005.00174.x. [PubMed: 16045632].

11. Rashidy-Pour A, Malek M, Eskandarian R, Ghorbani R. Obesity in the Iranian population. Obes Rev. 2009;10(1):2-6. doi: 10.1111/j.1467789X.2008.00536.x. [PubMed: 19021868].

12. Stevens GA, Singh GM, Lu Y, Danaei G, Lin JK, Finucane MM, et al. National, regional, and global trends in adult overweight and obesity prevalences. Popul Health Metr. 2012;10(1):22. doi: 10.1186/1478-7954-1022. [PubMed: 23167948]. [PubMed Central: PMC3543235].

13. Esteghamati A, Khalilzadeh O, Mohammad K, Meysamie A, Rashidi A, Kamgar M, et al. Secular trends of obesity in Iran between 1999 and 2007: National Surveys of Risk Factors of Noncommunicable Diseases. Metab Syndr Relat Disord. 2010;8(3):209-13. doi: 10.1089/met.2009.0064. [PubMed: 20085488].

14. Hasani-Ranjbar S, Jouyandeh Z, Abdollahi M. A systematic review of anti-obesity medicinal plants - an update. J Diabetes Metab Disord. 2013;12(1):28. doi: 10.1186/2251-6581-12-28. [PubMed: 23777875]. [PubMed Central: PMC3691594].

15. Wang Y, Beydoun MA. The obesity epidemic in the United Statesgender, age, socioeconomic, racial/ethnic, and geographic characteristics: A systematic review and meta-regression analysis. Epidemiol Rev. 2007;29:6-28. doi: 10.1093/epirev/mxm007. [PubMed: 17510091].

16. Caprio S, Daniels SR, Drewnowski A, Kaufman FR, Palinkas LA, Rosenbloom AL, et al. Influence of race, ethnicity, and culture on childhood obesity: Implications for prevention and treatment: A consensus statement of Shaping America's Health and the Obesity Society. 
Diabetes Care. 2008;31(11):2211-21. doi: 10.2337/dc08-9024. [PubMed: 18955718]. [PubMed Central: PMC2571048].

17. Noppa H, Bengtsson C. Obesity in relation to socioeconomic status. A population study of women in Goteborg, Sweden. J Epidemiol Community Health. 1980;34(2):139-42. doi: 10.1136/jech.34.2.139. [PubMed: 7400727]. [PubMed Central: PMC1052059].

18. Sobal J, Stunkard AJ. Socioeconomic status and obesity: A review of the literature. Psychol Bull. 1989;105(2):260-75. doi: 10.1037/00332909.105.2.260. [PubMed: 2648443].

19. Chen Y, Hong C, Ning Y, Su X. Meta-analysis of studies with bivariate binary outcomes: A marginal beta-binomial model approach. Stat Med. 2016;35(1):21-40. doi:10.1002/sim.6620. [PubMed: 26303591]. [PubMed Central: PMC5789784].

20. Gill T. Epidemiology and health impact of obesity: An Asia Pacific perspective. Asia Pac J Clin Nutr. 2006;15 Suppl:3-14. [PubMed: 16928656].

21. Bakhshi E, Etemad K, Seifi B, Mohammad K, Biglarian A, Koohpayehzadeh J. Changes in obesity odds ratio among Iranian adults, since 2000: Quadratic inference functions method. Comput Math Methods Med. 2016;2016:7101343. doi: 10.1155/2016/7101343. [PubMed: 27803729]. [PubMed Central: PMC5075634].

22. Bakhshi E, Mohammad K, Eshraghian MR, Seifi B. Factors related to obesity among Iranian men: Results from the National Health Survey. Public Health Nutr. 2010;13(9):1389-94. doi: 10.1017/S1368980010000108. [PubMed: 20441659].

23. Dalvand S, Koohpayehzadeh J, Karimlou M, Asgari F, Rafei A, Seifi $\mathrm{B}$, et al. Assessing factors related to waist circumference and obesity: Application of a latent variable model. J Environ Public Health. 2015;2015:893198. doi: 10.1155/2015/893198. [PubMed: 26770218]. [PubMed Central: PMC4681816].

24. Ahmadi M, Moosazadeh M, Vardanjani HM, Dehghan A. Prevalence of obesity and overweight and their related factors among the adults of Mazandaran province, Iran, in 2010. Electron Physician. 2014;6(4):95561. doi: 10.14661/2014.955-961. [PubMed: 25763175]. [PubMed Central: PMC4324264].

25. Veghari G, Sedaghat M, Joshaghani H, Hoseini A, Niknajad F, Angizeh $A$, et al. The prevalence and associated factors of central obesity in Northern Iran. Iran Cardiovasc Res J. 2010;4(4):164-7.

26. Khabazkhoob M, Fotouhi A, Hashemi H, Mohammad K. [Obesity and overweight in Teheran province 1382]. Iran J Diabetes Lipid Disord. 2008;7(3):315-24. Persian.

27. Abdollahi A, Behnampour N, Vaghari G, Bazr Afshan H. [Association of oesity with age, sex and education in Golestan province]. Iran J Endocrinol Metab. 2010;12(3):282-76. Persian.

28. Moghimi-Dehkordi B, Safaee A, Vahedi M, Pourhoseingholi A, Pourhoseingholi $\mathrm{M}$, Ashtari S, et al. Overweight and obesity and related factors in urban Iranian population aged between 20 to 84 years. Ann Med Health Sci Res. 2013;3(2):171-6. doi: 10.4103/2141-9248.113656. [PubMed: 23919184]. [PubMed Central: PMC3728857].

29. Hosseinpanah F, Barzin M, Eskandary PS, Mirmiran P, Azizi F. Trends of obesity and abdominal obesity in Tehranian adults: A cohort study. BMC Public Health. 2009;9:426. doi: 10.1186/1471-2458-9-426. [PubMed: 19930614]. [PubMed Central: PMC2801677].

30. Janghorbani M, Amini M, Willett WC, Mehdi Gouya M, Delavari A, Alikhani S, et al. First nationwide survey of prevalence of overweight, underweight, and abdominal obesity in Iranian adults. Obesity (Silver Spring). 2007;15(11):2797-808. doi: 10.1038/oby.2007.332. [PubMed: 18070771].

31. Azadbakht L, Mirmiran P, Shiva N, Azizi F. General obesity and central adiposity in a representative sample of Tehranian adults: Prevalence and determinants. Int J Vitam Nutr Res. 2005;75(4):297-304. doi: 10.1024/0300-9831.75.4.297. [PubMed: 16229347]

32. Khabazkhoob M, Emamian MH, Hashemi H, Shariati M, Fotouhi A. Prevalence of overweight and obesity in the middle-age population: A priority for the health system. Iran J Public Health. 2017;46(6):827-34. [PubMed: 28828326]. [PubMed Central: PMC5558077].

33. Reitsma JB, Glas AS, Rutjes AW, Scholten RJ, Bossuyt PM, Zwinderman AH. Bivariate analysis of sensitivity and specificity produces informative summary measures in diagnostic reviews. $J$
Clin Epidemiol.2005;58(10):982-90. doi:10.1016/j.jclinepi.2005.02.022. [PubMed: 16168343].

34. Ting Lee ML. Properties and applications of the sarmanov family of bivariate distributions. Commun Stat Theory Methods. 1996;25(6):120722. doi: $10.1080 / 03610929608831759$.

35. Tavassoli AA, Gharipour M, Khosravi A, Kelishadi R, Siadat ZD, Bahonar A, et al. Gender differences in obesogenic behaviour, socioeconomic and metabolic factors in a population-based sample of Iranians: The IHHP study. J Health Popul Nutr. 2010;28(6):602-9. doi: 10.3329/jhpn.v28i6.6609. [PubMed: 21261206]. [PubMed Central: PMC2995029]

36. Statistical Centre of Iran. The statistical center of Iran 2015-2016. Iran statistical year book. The Statistical Center of Iran; 2017.

37. Jafari-Adli S, Jouyandeh Z, Qorbani M, Soroush A, Larijani B, HasaniRanjbar S. Prevalence of obesity and overweight in adults and children in Iran; a systematic review.J Diabetes Metab Disord. 2014;13(1):121. doi: 10.1186/s40200-014-0121-2. [PubMed: 25610814]. [PubMed Central: PMC4301060].

38. Bakhshi E, Eshraghian MR, Mohammad K, Foroushani AR, Zeraati H, Fotouhi A, et al. The positive association between number of children and obesity in Iranian women and men: Results from the National Health Survey. BMC Public Health. 2008;8:213. doi: 10.1186/1471-2458-8213. [PubMed: 18554417]. [PubMed Central: PMC2447835].

39. Bakhshi E, Eshraghian MR, Mohammad K, Seifi B. A comparison of two methods for estimating odds ratios: Results from the National Health Survey. BMC Med Res Methodol. 2008;8:78. doi: 10.1186/1471-2288-8-78. [PubMed: 19032774]. [PubMed Central: PMC2613917].

40. Hajian-Tilaki KO, Heidari B. Prevalence of obesity, central obesity and the associated factors in urban population aged 20-70 years, in the north of Iran: A population-based study and regression approach. Obes Rev. 2007;8(1):3-10. doi: 10.1111/j.1467-789X.2006.00235.x. [PubMed: 17212790].

41. Apostolopoulou M, Savopoulos C, Michalakis K, Coppack S, Dardavessis T, Hatzitolios A. Age, weight and obesity. Maturitas. 2012;71(2):115-9. doi: 10.1016/j.maturitas.2011.11.015. [PubMed: 22226988].

42. Najafipour H, Yousefzadeh G, Forood A, Karamouzian M, Shadkam M, Mirzazadeh A. Overweight and obesity prevalence and its predictors in a general population: A community-based study in Kerman, Iran (Kerman coronary artery diseases risk factors studies). ARYA Atheroscler. 2016;12(1):18-27. [PubMed: 27114733]. [PubMed Central: PMC4834177].

43. Linn S, Fulwood R, Rifkind B, Carroll M, Muesing R, Williams OD, et al. High density lipoprotein cholesterol levels among US adults by selected demographic and socioeconomic variables. The Second National Health and Nutrition Examination Survey 1976-1980. Am J Epidemiol. 1989;129(2):281-94. doi: 10.1093/oxfordjournals.aje.a115133. [PubMed: 2912041].

44. Farhadian M, Moghimbeigi A, Aliabadi M. Mapping the obesity in iran by bayesian spatial model. Iran J Public Health. 2013;42(6):581-7. [PubMed: 23967425]. [PubMed Central: PMC3744254].

45. Fattahi F, Zarrati M. [Relation of body mass index, abdominal obesity, some nutritional habits and hypertension in 25-65 year old population of Tehran]. Koomesh. 2011;12(3):229-35. Persian.

46. al-Mahroos F, al-Roomi K. Overweight and obesity in the Arabian Peninsula: An overview. J R Soc Promot Health. 1999;119(4):251-3. doi: 10.1177/146642409911900410. [PubMed: 10673848].

47. Al-Nozha MM, Al-Mazrou YY, Al-Maatouq MA, Arafah MR, Khalil MZ, Khan NB, et al. Obesity in Saudi Arabia. Saudi Med J. 2005;26(5):8249. [PubMed: 15951877].

48. Erem C, Arslan C, Hacihasanoglu A, Deger O, Topbas M, Ukinc K, et al. Prevalence of obesity and associated risk factors in a Turkish population (trabzon city, Turkey). Obes Res. 2004;12(7):1117-27. doi: 10.1038/oby.2004.140. [PubMed: 15292476].

49. Yumuk VD, Hatemi H, Tarakci T, Uyar N, Turan N, Bagriacik N, et al High prevalence of obesity and diabetes mellitus in Konya, a central Anatolian city in Turkey. Diabetes Res Clin Pract. 2005;70(2):151-8. doi 10.1016/j.diabres.2005.03.030. [PubMed: 16188577]. 
50. Musaiger AO, Al-Mannai MA. Weight, height, body mass index and prevalence of obesity among the adult population in Bahrain. Ann Hum Biol. 2001;28(3):346-50. doi: 10.1080/030144601300119151. [PubMed: 11393341].

51. Sibai AM, Hwalla N, Adra N, Rahal B. Prevalence and covariates of obesity in Lebanon: Findings from the first epidemiological study. Obes Res. 2003;11(11):1353-61. doi: 10.1038/oby.2003.183. [PubMed: 14627756].

52. Garawi F, Devries K, Thorogood N, Uauy R. Global differences between women and men in the prevalence of obesity: Is there an association with gender inequality? Eur J Clin Nutr. 2014;68(10):1101-6. doi: 10.1038/ejcn.2014.86. [PubMed: 24918120].

53. Paeratakul S, Lovejoy JC, Ryan DH, Bray GA. The relation of gender, race and socioeconomic status to obesity and obesity comorbidities in a sample of US adults. Int J Obes Relat Metab Disord. 2002;26(9):1205-10. doi:10.1038/sj.ijo.0802026. [PubMed:12187397].

54. Talaei M, Rabiei K, Talaei Z, Amiri N, Zolfaghari B, Kabiri P, et al. Physical activity, sex, and socioeconomic status: A population based study. ARYA Atheroscler. 2013;9(1):51-60. [PubMed: 23696760]. [PubMed Central: PMC3653259].

55. Asgari F, Biglarian A, Seifi B, Bakhshi A, Miri HH, Bakhshi E. Using quadratic inference functions to determine the factors associated with obesity: Findings from the STEPS Survey in Iran. Ann Epidemiol. 2013;23(9):534-8. doi: 10.1016/j.annepidem.2013.07.006. [PubMed: 23958406].

56. Popkin BM, Paeratakul S, Zhai F, Ge K. A review of dietary and environmental correlates of obesity with emphasis on develop- ing countries. Obes Res. 1995;3 Suppl 2:145s-53s. doi: 10.1002/j.15508528.1995.tb00457.x. [PubMed: 8581770].

57. Delibasi T, Karaaslan Y, Ustun I, Koroglu E, Hosgor S. National prevalence of underweight, overweight and obesity in Turkey: Cross sectional study of a representative adult population. Cent Eur J Med. 2007;2(3):294-303. doi: 10.2478/s11536-007-0024-4

58. Dallosso HM, James WP. The role of smoking in the regulation of energy balance. Int J Obes. 1984;8(4):365-75. [PubMed: 6511171].

59. Manson JE, Stampfer MJ, Hennekens $\mathrm{CH}$, Willett WC. Body weight and longevity. A reassessment. JAMA. 1987;257(3):353-8. doi: 10.1001/jama.1987.03390030083026. [PubMed: 3795418].

60. Bakhshi E, Seifi B, Biglarian A, Mohammad K. Factors associated with obesity in Iranian elderly people: results from the national health survey. BMC Res Notes. 2011;4:538. doi: 10.1186/1756-0500-4-538. [PubMed: 22168800]. [PubMed Central: PMC3273491].

61. Klesges RC, Meyers AW, Klesges LM, La Vasque ME. Smoking, body weight, and their effects on smoking behavior: A comprehensive review of the literature. Psychol Bull. 1989;106(2):204-30. doi: 10.1037/0033-2909.106.2.204. [PubMed: 2678202].

62. Boyle CA, Dobson AJ, Egger G, Magnus P. Can the increasing weight of Australians be explained by the decreasing prevalence of cigarette smoking? Int J Obes Relat Metab Disord. 1994;18(1):55-60. [PubMed: 8130816].

63. Laaksonen M, Rahkonen O, Prattala R. Smoking status and relative weight by educational level in Finland, 1978-1995. Prev Med. 1998;27(3):431-7. doi:10.1006/pmed.1998.0288. [PubMed: 9612833]. 